$\xi=-1$

\title{
The research of clinker monominerals modified suspensions' rheological properties
}

\author{
Kosukhin M.M. ${ }^{*}$, Starostina I.V. ${ }^{1}$, Kosukhin A.M. ${ }^{1}$ \\ ${ }^{I}$ FSBEI HPE «Belgorod State Technological University named after V.G. Shukhov», \\ Belgorod, Russia (308012, Belgorod, Kostyukov str. 46), \\ *E-mail:mkosuhin@mail.ru
}

\begin{abstract}
The findings of studying the influence of the superplasticizers of various natures on rheological properties of clinker monominerals' water suspensions have been presented. It has been shown that the plasticizing activity of admixtures is determined by the nature and the specific surface of a monomineral and the nature of the admixture's hydrophilic groups, and for complex admixtures also with the ratio of individual components. The optimal admixture dosages for monomineral suspensions of clinker minerals change in the row $\mathrm{C}_{2} \mathrm{~S}, \mathrm{C}_{3} \mathrm{~S}, \mathrm{C}_{3} \mathrm{~A}, \mathrm{C}_{4} \mathrm{AF}$, which allows forecasting the influence of admixtures on rheological properties of systems with cements of various mineral compositions. The obtained data correlate with the research findings of the admixtures' influence on cements of various mineral composition, which allows deducing the influence of admixtures on the systems with other cements, and providing the economically and technologically feasible selection and consumption of admixtures depending on the type of cement and its mineral composition.
\end{abstract}

Keywords: Superplasticizers, Concrete Mix, Colloid-Chemical Properties, Plasticizing Activity, Rheological Properties.

\section{Introduction}

Nowadays the leading role in building industry and housing and utilities sector belongs to the application of the up-to-date homeproduced materials and technologies. This has become especially relevant at present, within the framework of materials and technologies import phase-out. Concrete and reinforced concrete have always been extensively used both in new construction, and in carrying out reconstruction works. Among the great variety of building materials they have always played a major role in building industry. At the same time, concrete is the most complex artificial composite material, having a wide range of unique maintenance and engineering properties. A number of up-to-date requirements are also specified for the present-day concrete. Besides, with the development of in-situ concrete works in recent years, the concrete technology has been moved from factory environment to open construction sites, where it is made more complicated due to lack of stationary conditions for structure formation and strength gain processes [1-2].

To meet the above mentioned requirements nowadays a wide range of various chemical admixtures are used in concrete technology, and first of all, superplasticizers (SP) and complex admixtures based on them [3-5].

The admixtures' mechanism of action on concretes and concrete mixes properties depends on a number of factors. Due to the fact that the admixtures work at the level of the «cement-water» system, the defining role in their efficiency is played by the mineral and material composition of the used cement. In this regard, the purpose of this work consisted in determining the influence of superplasticizers of various natures on rheological properties of clinker monominerals suspensions. This would allow the economically and technologically feasible selection of the admixture type and amount for a certain type of cement with the given mineral and material composition.

\section{Material and Methods}

In the course of the research work the colloid and chemical properties of modified monomineral suspensions of clinker minerals, contained in various amounts in different types of cement and having considerable influence on the chemical additives' mechanism of action, have been studied.

The flowability of modified cement suspensions was researched by mini-cone method, according to the Gosstroy's Concrete and Reinforced Concrete Research Institute (CRCRI) methodology [6], which consists in determining the spread diameter of a cement suspension under the action of gravity.

The rheological properties of cement grouts and mortars were researched and the batching of cement concrete was carried out according to the methodology, developed in CRCRI, concerning the application of admixtures of various kinds in pre-cast and mass concrete technology [7].

The admixtures' mechanism of action was studied by the results of standard research tests for colloid and chemical properties of modified mineral suspensions.

The rheological parameters of suspensions were researched by using a rotation viscometer «Reotest-2». The concentration of $\mathrm{SP}_{(\mathrm{Cm})}$ was calculated in per cent for weight for dry matter from the amount of dispersion phase. In the course of the research the dependence between shear stress value and shearing rate was determined. On the basis of the obtained findings the rheological curves were plotted, by means of which the yield value $[\mathrm{tau}]_{0}$ and plastic viscosity [eta $]_{\mathrm{pv}}$ were found.

To find the electrokinetic properties of the surface the flow potential method was used with account of the surface conductivity, 
which allows determining [zeta]-potential in concentrated suspensions.

To determine the composition and structure of oligomeric molecules the liquid and gas-liquid chromatography, ultraviolet and infrared spectroscopy, NMR-spectroscopy, conductometry and potentiometry were used. The molecular weight of the synthesized oligomers was determined by means of cryoscopy.

The modifiers' mechanism of action was determined by means of physical and chemical research methods. For this purpose the water solutions of modifiers, the hardening kinetics of cement paste, the alteration of phase composition of cement stone samples with additives, the phase transformations in models systems and clinker minerals at hydration and hardening were studied.

\section{Results and discussion}

To forecast the influence of admixtures on rheological properties of cements of various mineral compositions, the influence of admixtures on the rheology of clinker minerals water suspensions was researched. The research findings, presented in Fig. 1-4, allow contributing to the study of superplasticizers mechanism of action.

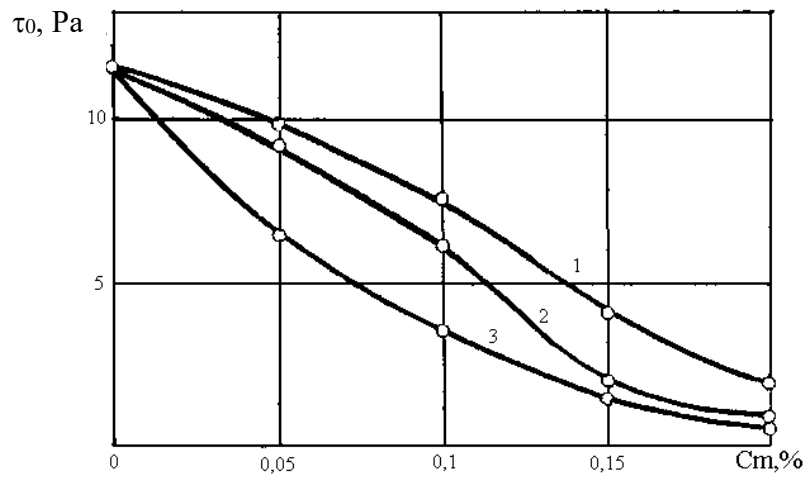

Fig. 1: The dependence of the yield value of $\mathrm{C}_{3} \mathrm{~S}$ suspensions at water/solid ratio $=0.48$ on the admixture dosage: $1-\mathrm{S}-3 ; 2-\mathrm{SB}-3$; $3-\mathrm{S}-3+\mathrm{SB}-3$

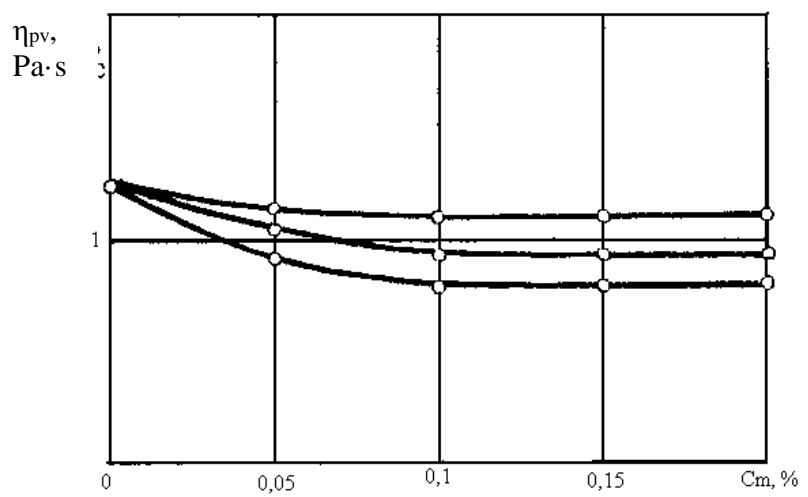

Fig. 2: The dependence of the plastic viscosity of $\mathrm{C}_{3} \mathrm{~S}$ suspensions at water/solid ratio $=0.48$ on the admixture dosage: $1-\mathrm{S}-3 ; 2-\mathrm{SB}-3$; $3-\mathrm{S}-3+\mathrm{SB}-3$.

This may be due not only to the adsorption of S-3 on the surface of hydroaluminates, but to the interaction of S-3 with the ions in solution which results in the formation of slightly-soluble compounds. The information of such interactions can be found in [10]. The influence of SP admixtures on cement suspensions has been studied at different times by various researchers and scientific schools since their appearance and the beginning of their use for cement concretes and mortars.

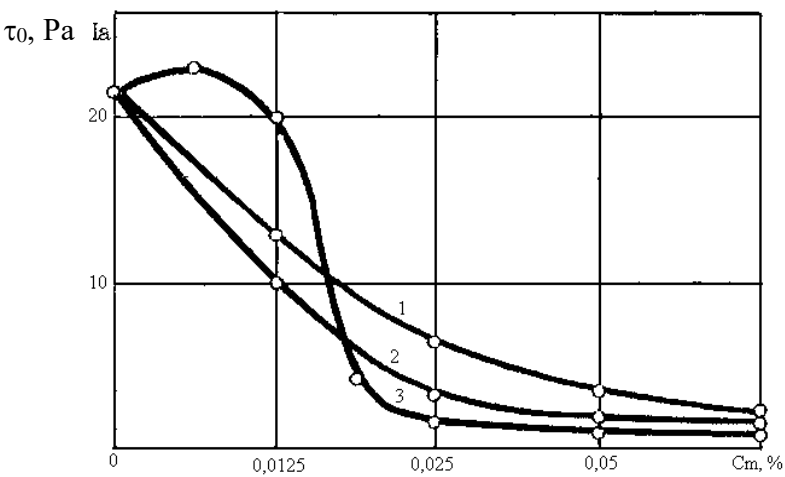

Fig. 3: The dependence of the yield value of $\mathrm{C}_{3} \mathrm{~S}$ suspensions at water/solid ratio $=0.25$ on the admixture dosage: $1-\mathrm{S}-3 ; 2-\mathrm{SB}-3$; $3-\mathrm{S}-3+\mathrm{SB}-3$

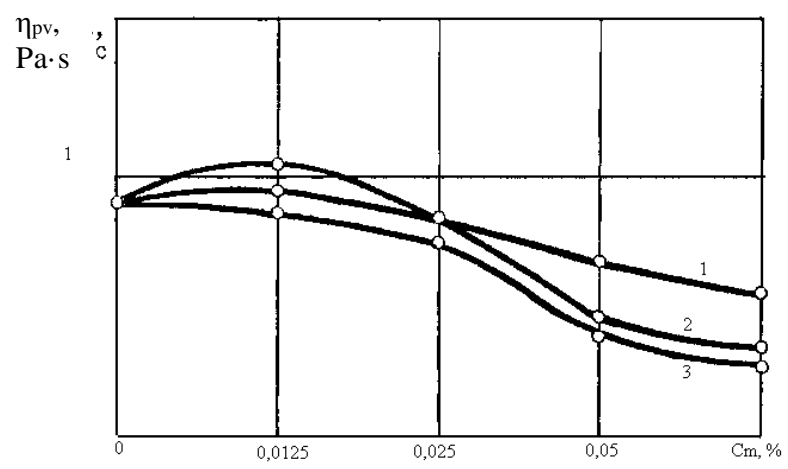

Fig. 4: The dependence of the plastic viscosity of $\mathrm{C}_{3} \mathrm{~S}$ suspensions at water/solid ratio $=0.25$ on the admixture dosage: $1-\mathrm{S}-3 ; 2-\mathrm{SB}-3$; $3-\mathrm{S}-3+\mathrm{SB}-3$

Nevertheless, at present there is no single generally accepted theory of their mechanism of action. At first the adsorption-solvation factor was favored by the scientists. Then, according to many researchers, the electrostatic factor has been considered the determining one [11 - 13].

The experimental research [14] demonstrates that the mechanism of the admixtures' plasticizing activity is conditioned only by the combined action of adsorption-solvation and electrostatic factors. The analysis of the research findings shows that the molecular adhesive attraction energy can be overcome only by the joint action of the charging energy and the structure interaction energy. This is proved with experimental data [15]. The admixtures' molecules are adsorbed on the surface of particles, forming a monomolecular layer. The adsorption of admixtures on the surface of particles is ensured by the dispersion forces of interaction between the admixture's aromatic rings system and the particles surface. As the admixtures are anion-active substances, the charge of the particles surface becomes more negative, which results in the increase of the particles' repulsion forces. The formation of hydrate layers over the particles due to the presence of hydrophilic groups in the admixture's molecules also contribute to this process. As a result, the repulsion forces begin to exceed molecular attraction forces, which reduce the coagulation contact energy to the values, comparable with thermal motion energy. At that, the transition to full aggregative stability of the system is observed; the aggregates are peptized to primary particles; the rheological flow behavior of suspension is changed from Bingham (the yield value is over zero) to Newtonian (the yield value amounts to zero). The efficiency of admixtures is greatly determined by the nature of hydrophilic groups; and among them the hydroxyl groups are the most efficient. As our research has demonstrated, during the admixtures' adsorption the «adsorbate-adsorbate» interaction on the surface of the disperse phase should not be ignored. Taking this phenomenon into account and selecting the individual components properly 
allows obtaining complex admixtures with the pronounced synergistic effect.

\section{Conclusion}

So, the research of the admixtures influence on the rheology of clinker minerals suspensions has shown that the admixtures' plasticizing activity is determined with the nature and the specific surface of the mineral, the nature of the admixture's hydrophilic groups, and for complex admixtures also with the ratio of individual components. The obtained findings correlate with the research findings of the admixtures' influence on cements of various mineral compositions and allow forecasting results for other cements, as well as contributing to the study of the superplasticizers mechanism of action.

\section{Acknowledgement}

The article has been prepared within the framework of the Flagship University Development Program on the basis of BSTU named after V.G. Shukhov.

\section{References}

[1] Kosukhin M.M., Kosukhin A.M., "Theoretical and methodological basis of creating polyfunctional modifiers of mass concretes for reconstruction works", Bulletin of BSTU named after V.G. Shukhov, No.1, (2017), pp. 23-32.

[2] Kosukhin M.M., Komarova N.D., Kosukhin A.M., Komarova K.S., "On the question of designing polyfunctional modifiers of mass concretes for reconstruction works of housing and utility objects", BTB: Building technology bulletin, No.5, (2017), pp. 37-44.

[3] Kosukhin M.M., Shapovalov N.A., Kosukhin A.M., Sharapov O.N., "The effect of superplasticizer hydrophilic group nature on its plasticizing activity", International Journal of Pharmacy \& Technology Sep., Vol. 8, No. 3, (2016), pp. 15271-15286.

[4] Kosukhin M.M., Shapovalov H.A., Kosukhin A.M., Babin A.A., "Superplasticizer for concretes based on light pyrolysis resin", Building materials, No.7, (2008), p. 44.

[5] Kosukhin M.M. Shapovalov N.A. Kosukhin A.M., "Colloidchemical bases on creation of multifunctional modifiers of concrete mix and concrete", Solid State Phenomena, Vol. 265, (2017), pp. 331-336.

[6] Recommendations on control of physical and chemical composition and quality of $S$-3 superplasticizer, Moscow: CRCRI, (1984).

[7] Methodological recommendations on evaluating the additives efficiency, Moscow: CRCRI, (1979), p.24.

[8] Kosukhin M.M., Kosukhin A.M., "Studying the influence of superplasticizers of various nature on the rheology of clinker minerals waters suspensions", Bulletin of BSTU named after V.G. Shukhov, No.10, (2017), pp. 129-133.

[9] Batrakov V.G., Modified concretes, Moscow: Stroyizdat, (1990), p. 400.

[10] Ramachandran V.S., Feldman R.F., Collepardi M. and others, Concrete admixtures handbook: Handbook / Ed. by V.S. Ramachandran: Trans. from English by G.I. Rozenberg, S.A. Boldyrev: Ed. by S.A. Boldyrev, V.B. Ratinov, Moscow: Stroyizdat, (1988), p. 575.

[11] Roy D., Daimon M., Asaga K., "The influence of admixtures on electrokinetic phenomena at the hydration of $\mathrm{C} 3 \mathrm{~S}, \mathrm{C} 3 \mathrm{~A}$ and cement", Proceedings of the 7th International congress of cement chemistry, No.790, (1980), p.15.

[12] Costa U., Bassila A., "Interaction between superplasticizers and calcium albuminate hydrates", I. of the Amer.Cer. Soc., No. 62, (1982), pp. 203-207.

[13] Daimon M., Roi D., "Rheological properties of cement mixes. II. zeto-potential 'and preliminary viscosity studies", Cement and Conerete Res., No.1, (1979), pp. 103-109.

[14] Kosukhin M.M., Regulating the properties of concretes and concrete mixes with complex additives with various hydrophilic groups: thesis.... of cand. of tech. sciences, Voronezh, (1995), p.173.

[15] Efremov I.F., Periodic colloidal structures, L.: «Chemistry», (1971), p.192. 